Where are their staging areas in Morocco? Is Morocco acting as a sink for the Spanish population? Could these dispersal movements be the start of new breeding colonies in northern Morocco? Most importantly, could these birds contact the unique and isolated wild colonies in southern Morocco and interbreed with them? Considering the precarious conservation status of the northern bald ibis, and the severe environmental impacts northern Morocco is suffering, it is time to commence cross-border collaboration and conservation action for this Critically Endangered species.

Antonio-RomÁn Muñoz and JuAN RAmírez Departamento de Botànica, Facultad de Farmacia, Universidad de Valencia, Valencia,Spain.E-mail roman@uma.es

\section{Discovery of a second population of the Critically Endangered Madagascan suicide palm Tahina spectabilis}

Researchers from the Royal Botanic Gardens, Kew, the Parc Botanique et Zoologique de Tsimbazaza, and the University of the Sunshine Coast, Australia, have discovered a new site for the Critically Endangered palm Tahina spectabilis. With its nearest living relatives in Asia and the Middle East, the discovery and publication of Tahina (Dransfield et al., 2008, Botanical Journal of the Linnean Society, 156, 79-91), a new monotypic fan palm genus in Madagascar, stunned the international palm community and intrigued the media (the latter dubbing the species 'the Madagascan suicide palm' as a result of the plant's hapaxanthic life history, whereby adults die after flowering).

Tahina spectabilis can reach up to $18 \mathrm{~m}$ in height, with leaves up to $5 \mathrm{~m}$ across, and the crown of the palm is so large that individuals can be seen in images on Google Earth. With fewer than 30 trunked individuals recorded in the wild, at a geographically restricted and vulnerable site on a remote peninsula in north-west Madagascar, T. spectabilis is categorized as Critically Endangered on the IUCN Red List. It is not understood what triggers the species' rare flowering events, but when the palm does flower, it has the capacity to produce enormous numbers of propagules. Kew worked with the local cashew plantation company VERAMA and the local community to collect seed from a successful fruiting event in 2007 and these were sold internationally, with the funds returning to the community to fund conservation and development activities at the site.

Ten years on, a Kew expedition set off in September 2016, with the support of the Mohamed bin Zayed Species Conservation Fund, to re-census the known T. spectabilis population and check on the progress of the conservation work. The team found that, although the population at the original site is still small, it is stable and probably increasing slowly, with nearly 700 individuals recorded. Five adults have flowered and died since the last census in 2008, but another five juvenile individuals have grown sufficiently to be classed as adults. The local community have been protecting the site, with a wide firebreak maintained around the population, and fences built to keep grazing zebu from trampling young plants. At a site nearby, the team found 170 seedlings, and the local community has agreed to monitor and protect this site as well. Income from seed sales has been managed by VERAMA, and has funded several infrastructure projects, including the construction of a school and the digging of a well for the village, and provided ongoing annual funding for the maintenance of the firebreak and fences.

After visiting the original type location of Tahina, the Kew expedition investigated reports of another population of T. spectabilis further inland, just $10 \mathrm{~km}$ from Madagascar's Route National 6 that connects the capital Antananarivo with Ambanja in the north. With the help of local people a small, but unmistakable, group of 25 individuals was discovered in a remote fragment of forest, including five adults, the largest being a medium-sized adult c. $12 \mathrm{~m}$ in height. Initial discussions with the local community about the importance of the species' conservation went well. A follow-up trip in October by another Kew team reinforced and continued these initial discussions, and investigated the needs of the community and how conservation and development work could be brought together at this new site. It is hoped that funding will soon be secured to help with the early stages of this work.

A demographic and genetic study across the two populations and a species conservation management plan are now being prepared. Species distribution models will be run using the currently known geographical range of $T$. spectabilis, and the results used to identify and explore other sites where the species could potentially grow. Although it is highly significant that a second Tahina population exists, it is unlikely that the Red List status of T. spectabilis will change as a result of this new discovery. Even with a much larger Extent of Occurrence for the species, the number of mature individuals known in the wild still remains extremely low at only 34 , and therefore T. spectabilis remains Critically Endangered according to the IUCN Red List Criterion D.

LaURen M. Gardiner Royal Botanic Gardens, Kew, Richmond, Surrey, UK. E-mail l.gardiner@kew.org

DAVID RABEHEVITRA Kew Madagascar Conservation Centre, Ivandry, Antananarivo, Madagascar

Rokiman Letsara Parc Botanique et Zoologique de Tsimbazaza / California Academy of Sciences-Madagascar, Antananarivo, Madagascar 
ALISON SHAPCOTT University of the Sunshine Coast, Queensland, Australia

\section{Outbreeding ideas for conservation success}

It is increasingly recognized that interdisciplinarity is needed to tackle global challenges (Ledford, 2015, Nature, 525, 308-311), a daunting example being the problems of conserving biodiversity. However, walls between disciplines have proven no less difficult to tear down than those between nations (Reagan, 1987, Remarks at Brandenburg Gate, Berlin, Germany, 06/12/1987. www.archives.gov/historicaldocs/todays-doc/index.html?dod-date $=612$ ). Interdisciplinary research suffers consistently low funding success (Bromham et al., 2016, Nature, 534, 684-687) and there are still philistines who perceive it as the province of researchers 'who aren't good enough to make it in their own field' (Ledford, 2015, Nature, 525, 308-311).

Challenging this stubborn disciplinary cartography remains, unfortunately, the exception in applied conservation research. As an illustration, the three international conferences that the University of Oxford's Wildlife Conservation Research Unit (WildCRU) organized during the past 15 years on canid, felid and mustelid conservation hosted, despite our best efforts, only a handful of delegates (out of nearly 1,00o) with backgrounds genuinely beyond the biological sciences. Conservation scientists are sowing the seeds of inbred ideas that are decreasingly likely to germinate in today's complex world.

Emboldened by urgency and the prospect of gridlock (Hale et al., 2013, Gridlock: Why Global Cooperation is Failing when We Need It Most. Polity Press), WildCRU and the international NGO Panthera recently experimented with an alternative meeting format in an attempt to break the mould and identify innovative conservation strategies to prevent the extinction of lions Panthera leo in Africa (Bauer et al., 2015, Proceedings of the National Academy of Sciences of the United States of America, 112, 1489414899). In what we call the Oxford Format (named after its venue, in the tradition of diplomatic mechanisms; e.g. the Normandy Format to tackle the crisis in Ukraine), c. 30 lion insiders (ecologists, zoologists, geneticists from WildCRU and Panthera) brainstormed during 3 days with 30 lion outsiders (leading international political scientists, economists, philosophers, development experts) at the Cecil Summit (www.ox.ac.uk/news/science-blog/cecilsummit-another-key-milestone-lion-conservationmovement). The format began with short presentations by insiders (both researchers and those working with communities living alongside lions) on the lion's predicament, followed by short presentations by outsiders to provide radically different perspectives on this predicament. The unfolding discussions blended ideas that led to recasting lion conservation as an issue fundamentally framed by economics and governance. Paradoxically, none of these discussions focused on lion ecology but all were critically relevant to lion survival in an increasingly crowded African continent.

Although stimulating novel ideas is a far cry from implementing them, the success of the first Oxford Format summit in generating outbred ideas convinces us that the prize will be won by forcing, rather than by simply urging, interdisciplinarity to address conservation issues. There is no excuse left for inbred conservation thinking.

DAVID W. MACDONALD WildCRU, Department of Zoology, University of Oxford, The Recanati-Kaplan Centre, Tubney, Abingdon, UK

E-mail david.macdonald@zoo.ox.ac.uk

Guillaume Chapron Department of Ecology, Grimsö Wildlife Research Station, Swedish University of Agricultural Sciences, Riddarhyttan, Sweden

\section{Singapore hosts international efforts for conserving migratory waterbirds in the Asia-Pacific}

Two major international meetings targeted at the region's migratory birds have recently been hosted in Singapore, a country that has a key role in conserving waterbirds migrating from as far north as Siberia to as far south as Tasmania. What happens in the Arctic does not stay in the Arctic, and the other way around, is the mantra underpinning the conservation of Arctic breeding birds under the Conservation of Arctic Flora and Fauna working group, part of the Arctic Council, to which Singapore is an observer. This goal is being pursued through the Arctic Migratory Bird Initiative, which met on 8-9 January to discuss pressing issues in the East Asian-Australasian Flyway. Hunting of migratory waterbirds was reported from multiple countries across the flyway, raising concerns about their survival. Addressing unsustainable hunting is one of the key objectives of this Initiative, and a recommendation was made, with support from the Convention on Migratory Species, to establish a working group drawing on lessons from experience in the Mediterranean (Bird Conservation International, 2016, 26, 1-28).

The 9th Meeting of the Partners of the East AsianAustralasian Flyway Partnership took place during 11-15 January. This is a multi-actor voluntary agreement for conserving migratory waterbirds in the 22 countries of the East Asian-Australasian Flyway. The Partnership primarily focuses on habitat conservation, which remains a pressing issue, particularly in the Yellow Sea. The membership of the Partnership continues to grow, with the Hanns Seidel Foundation joining since the last Meeting. This nongovernmental organization is playing an important role through conservation and capacity building initiatives in 